\title{
Sliding Mode Control of Strip Rolling Mill Hydraulic AGC System
}

\author{
Liping Fan ${ }^{1, *}$, Ming Fang ${ }^{2}$ and Yi Liu ${ }^{3}$ \\ ${ }^{1}$ College of Environment and Safety Engineering, Shenyang University of Chemical \\ Technology, Shenyang 110142, China \\ ${ }^{2}$ College of Information Engineering, Shenyang University of Chemical Technology, \\ Shenyang 110142, China, \\ ${ }^{3}$ Branch Company of Rolling Equipment, North Heavy Industry Group Co., Ltd, \\ Shenyang, 110141, China. \\ *flpsd@163.com
}

\begin{abstract}
Hydraulic automatic gauge control $(A G C)$ is a very important part of rolling mill for magnesium plate rolling. The control effect of automatic gauge control system influences the quality of the rolled product directly. AGC system is an essentially nonlinear, time delay, time-varying, large inertia, multivariable and coupling complex system, which increase the designing difficulty of control system. Based on the mathematical model of the automatic gauge control system, a simulation platform of rolling mill is set up, and a sliding mode variable structure controller is designed to realize position control for the hydraulic automatic gauge control system. The control effect of the proposed sliding mode controller is compared with that of a general PID controller whose parameters was adjusted by ZieglerNichols method. Simulation results show that the sliding mode controller has strong antiinterference ability and can give satisfactory control effect.
\end{abstract}

Keywords: Strip Rolling Mill; Hydraulic AGC System; Sliding Mode Control

\section{Introduction}

Rolled products are the types of structural materials produced in the largest quantities and are widely used in machine-building, metal-working, construction, transportation, and other sectors of the national economy. Rolled products are also used in metallurgical production itself for further conversion into tubes, hardware, tin plate, etc., [1]. Magnesium alloys is by far the lightest structural metallic materials in engineering applications, it has been used in the defense, aerospace, high-speed trains, cars and electronic communications and other fields widely, and it is known as the most potential "Green metal structural materials" for development and application in the 21 st century. The growing demand for magnesium alloy sheet gives higher requirements on rolling technology. It is necessary to improve the overall operation of precision rolling mill equipment. In recent years, with the rapid development of industries, higher accuracy requirements on the overall operation of the magnesium plate rolling mill are put forward.

Hydraulic pressure automatic gauge control (AGC) system, with high accuracy, fast response, etc., becomes the core technology of strip rolling mill [2], and it is still the key part of a magnesium plate rolling mill. Currently, most of the more advanced mills have adopted

* Corresponding author 
the hydraulic pressure control system. Its performance has a direct impact on product quality of the rolled magnesium board and the production efficiency of the mill.

Control technology for strip mill hydraulic pressure automatic gauge control has experienced by the coarse-to-fine process of development. The traditional thickness control systems generally use the classic PID controller. Conventional PID control has the advantages of simplicity, convenience, suitability and robustness, etc., so it is widely adopted for industrial process control. AGC system is an essentially nonlinear, time delay, time-varying, large inertia, multivariable and coupling complex system [3]. As the complexity of the control object, the precise mathematical model of the control system cannot be established, and there are some disturbances caused by internal parameters and external load and some other uncertainties. These factors increase the designing difficulty of control system [4-6]. Because of the existing of some difficulties such as parameters tuning, traditional PID control have been increasingly unable to meet the control requirements [7-8].

Sliding mode controller is a kind of nonlinear controller which was introduced for controlling variable structure systems (VSSs). SMC is one of the effective nonlinear robust control approaches since it provides system dynamics with an invariance property to uncertainties once the system dynamics are controlled in the sliding model [9].The sliding mode can be designed and has nothing to do with the controlled object parameters and disturbances, and this makes the sliding mode control have some advantages such as fast response, insensitivity to parameter variations and disturbances, and it has been successfully applied to robotics, power systems, and many other practical systems [10-16].

A position controller for the hydraulic AGC system is designed based on the sliding mode control theory. This paper is organized as follows. The mathematical model for a typical hydraulic pressure system is described in Section 2. Section 3 presents a brief description of designing a sliding mode controller for AGC. Simulation results are presented in section 4 to confirm the effectiveness and the applicability of the proposed method. Finally, our work of this paper is summarized in the last section.

\section{Modelling of the AGC System}

A complete hydraulic AGC control system consists of some parts such as oil pipeline, hydraulic cylinders, rolling wheels, oil return pipe, and displacement sensor [17]. The principle diagram of position control on a hydraulic AGC system is shown in Figure 1.

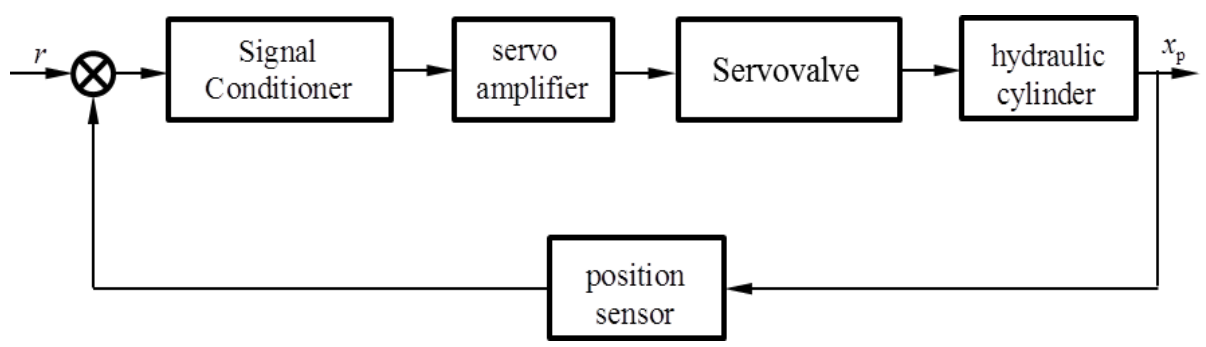

Figure 1. Schematics of Position Control of a Hydraulic AGC System

\subsection{Servo Valve}

The load flow of a servo valve can be described as [17-19]

$$
Q_{\mathrm{L}}=C_{\mathrm{d}} W x_{\mathrm{v}} \sqrt{\frac{P_{\mathrm{s}}-P_{\mathrm{L}}}{\rho}}
$$


where $Q_{\mathrm{L}}$ is the load flow of a servo valve, $W$ is the area gain of the amplifier stage slide valve, $C_{\mathrm{d}}$ is flow coefficient, $P_{\mathrm{s}}$ is charge oil pressure, $P_{\mathrm{L}}$ is load pressure, $x_{\mathrm{v}}$ is spool displacement, $\rho$ is oil density.

Servo valve has a characteristic of high nonlinearity. To facilitate the design of controllers, $Q_{\mathrm{L}}$ is linearized as

$\Delta Q_{\mathrm{L}}=Q_{\mathrm{sv} 0}-K_{\mathrm{c}} \Delta P_{\mathrm{L}}$

$Q_{\mathrm{sv} 0}=K_{\mathrm{sv}} I_{\mathrm{c}}$

where $Q_{\mathrm{sv} 0}$ is the idle load flow, $I_{\mathrm{c}}$ is the input current, $K_{\mathrm{sv}}$ is the static flow amplification factor of the servo valve, $K_{\mathrm{c}}$ is the pressure flow factor, $\Delta P_{\mathrm{L}}$ denotes the change of load pressure.

In general, if the natural frequency $w_{\mathrm{h}}$ of a hydraulic actuator is less than $50 \mathrm{~Hz}$, the dynamic characteristic of the servo valve can be described as the following first-order element

$\frac{Q_{\mathrm{sv} 0}}{I_{\mathrm{c}}}=\frac{K_{\mathrm{sv}}}{1+s / w_{\mathrm{sv}}}$

When the natural frequency $w_{\mathrm{h}}$ of a hydraulic actuator is greater than $50 \mathrm{~Hz}$, the dynamic characteristic of the servo valve can be described as the following second-order link

$$
\frac{Q_{\mathrm{sv} 0}}{I_{\mathrm{c}}}=\frac{K_{\mathrm{sv}}}{\frac{s^{2}}{w_{\mathrm{sv}}^{2}}+\frac{2 \zeta_{\mathrm{sv}}}{w_{\mathrm{sv}}} s+1}
$$

\subsection{Hydraulic Cylinder}

The actual change of the controlled volume is

$$
\Delta V=V_{Q}-\Delta V_{\mathrm{c}}-V_{\mathrm{cl}}=x_{\mathrm{p}} A_{\mathrm{p}}
$$

The total volume $V_{Q}$ delivered to the cylinder is the integration of flow $\Delta Q_{\mathrm{L}}$, that is

$V_{Q}=\int \Delta Q_{\mathrm{L}} \mathrm{d} t$

The amount of compression fluid in the controlled volume is

$$
\Delta V_{\mathrm{c}}=\frac{V_{\mathrm{e}}}{E_{0}} \Delta P_{\mathrm{L}}
$$

where, $V_{\mathrm{cl}}$ is leakage of fluid in the controlled volume, $x_{\mathrm{p}}$ is the displacement of the hydraulic cylinder piston, $A_{\mathrm{p}}$ is the area of the hydraulic cylinder piston, $V_{\mathrm{e}}$ is the equivalent controlled volume of the hydraulic cylinder, $E_{0}$ is the elasticity modulus of the fluid.

Because the servo valve usually works near the point of zero position, the parameter increment is also its absolute quantity. So, the following continuity equation of the hydraulic cylinder flow can be derived by the above mentioned equations 
$Q_{\mathrm{L}}=A_{\mathrm{p}} \frac{\mathrm{d} x_{\mathrm{p}}}{\mathrm{d} t}+K_{\mathrm{ce}} P_{\mathrm{L}}+\frac{V_{0}}{E_{0}} \frac{\mathrm{d} P_{\mathrm{L}}}{\mathrm{d} t}$

where, $V_{0}$ is the initial volume of the controlled chamber, $K_{\mathrm{ce}}$ is the internal leakage coefficient of the hydraulic cylinder. Find the Laplace transform for equation (9) and then

$Q_{\mathrm{L}}=A_{\mathrm{p}} x_{\mathrm{p}} s+K_{\mathrm{ce}} P_{\mathrm{L}}+\frac{V_{0}}{E_{0}} P_{\mathrm{L}} s$

\subsection{Load Force Equation}

The rolling force output from the cylinder must maintain balance with the load force. Load force is composed of the inertia force of moving parts, the viscous friction force, the elastic load force and some other load force. The change of the output force of the hydraulic cylinder is

$\Delta F=\Delta F_{\mathrm{p}}-\Delta F_{\mathrm{b}}=\Delta P_{\mathrm{L}} A_{\mathrm{p}}-\Delta P_{\mathrm{b}} A_{\mathrm{b}}$

where, $\Delta F_{\mathrm{p}}$ is the change of rodless cavity force, $\Delta F_{\mathrm{b}}$ is the change of rod cavity force, $\Delta P_{\mathrm{b}}$ is the change of back-pressure of the rod cavity, $A_{\mathrm{b}}$ denotes the working area of the rod cavity.

The force balance equation is

$\Delta F=M_{\mathrm{C}} \frac{\mathrm{d}^{2} x_{\mathrm{p}}}{\mathrm{d} t^{2}}+B_{\mathrm{p}} \frac{\mathrm{d} x_{\mathrm{p}}}{\mathrm{d} t}+K_{\mathrm{t}} x_{\mathrm{p}}+F_{\mathrm{L}}$

where $M_{\mathrm{C}}$ is the total mass of the moving parts in rolls, $t$ is the movement time of the piston, $B_{\mathrm{p}}$ is the viscosity coefficient of moving parts such as piston and load, $K_{\mathrm{t}}$ is the stiffness coefficient of elastic load. $F_{\mathrm{L}}$ denotes other loads applied to the piston, and it can be described as

$F_{\mathrm{L}}=W \Delta h=W\left(h_{\text {in }}-h_{\text {out }}\right)+K_{\mathrm{f}}$

If the elastic recovery can be ignored, then the exit thickness $h_{\text {out }}$ of the rolled piece is equal to the loaded roll gap $h_{\mathrm{L}}$, then

$h_{\mathrm{L}}=h_{\mathrm{s}}-\left(x_{\mathrm{p}}-\Delta h_{\mathrm{j}}\right)$

where, $h_{\mathrm{s}}$ is the setting value of the roll gap, $\Delta h_{\mathrm{j}}$ is the mill bounce quantity caused by rolling force change.

Because the longitudinal stiffness coefficient $M_{\mathrm{p}}$ of the mill decreases with the increase of working stroke of screwdown cylinder, it can be estimated by

$$
\begin{aligned}
& \frac{1}{M_{\mathrm{p}}}=\frac{1}{M_{0}}+\frac{L_{\mathrm{p}}}{E_{0} A_{\mathrm{P}}} \\
& L_{\mathrm{P}}=L_{0}+x_{\mathrm{p}}
\end{aligned}
$$

where $M_{0}$ is longitudinal stiffness corresponding to zero working stroke, $L_{\mathrm{p}}$ is the working stroke of screwdown cylinder, and $L_{0}$ is the preload stroke of the screwdown cylinder. 


\subsection{Back Pressure Return Oil Pipe}

The back pressure return oil pipe in hydraulic AGC system can be designed by several kinds of approaches, and to form constant backpressure through overflow valve control is one of the most commonly used methods. Backpressure is a kind of low pressure, fluid in pipe can be regarded as incompressible fluid. By using continuity equation and Bernoulli equation, the backpressure can be derived as

$$
\begin{aligned}
& P_{\mathrm{d}}=P_{\mathrm{d} 0}+M_{\text {or }} \frac{\mathrm{d}^{2} x_{\mathrm{p}}}{\mathrm{d} t^{2}}+R_{\mathrm{r}} \frac{\mathrm{d} x_{\mathrm{p}}}{\mathrm{d} t} \\
& M_{\text {or }}=\frac{\rho L_{\mathrm{r}} A_{\mathrm{b}}}{A_{\mathrm{r}}}
\end{aligned}
$$

where $P_{\mathrm{d} 0}$ is the initial back pressure, $M_{\mathrm{or}}$ is the fluid mass of return oil pipe, $L_{\mathrm{r}}$ is the length of return oil pipe, $A_{\mathrm{r}}$ is the cross-sectional area of return oil pipe, and $R_{\mathrm{r}}$ is pressure coefficient.

\subsection{Displacement Sensor}

Displacement sensor can be regarded as an inertial element:

$$
\frac{x_{\mathrm{d}}}{x_{\mathrm{p}}}=\frac{K_{\mathrm{s}}}{1+T_{\mathrm{s}} \mathrm{s}}
$$

where $x_{\mathrm{d}}$ is the output displacement of sensor, $K_{\mathrm{s}}$ is a displacement feedback coefficient, and $T_{\mathrm{s}}$ is the time constant of displacement sensor.

\subsection{Dynamic Model of Hydraulic AGC System}

According to the models of the above elements, the dynamic model of AGC system can be described as

$$
X_{\mathrm{p}}(s)=\frac{N(s)}{D(s)}
$$

with

$$
\begin{aligned}
& N(s)=\frac{K_{\mathrm{sv}}}{A_{\mathrm{p}}} I_{\mathrm{c}}-\frac{K_{\mathrm{ce}}}{A_{\mathrm{p}}^{2}}\left(1+\frac{V_{0}}{E_{0} K_{\mathrm{ce}}} s\right)\left(F_{\mathrm{L}}+P_{\mathrm{b}} A_{\mathrm{b}}\right) \\
& D(s)=\frac{V_{0} M_{\mathrm{e}}}{E_{0} A_{\mathrm{p}}^{2}} s^{3}+\left(\frac{M_{\mathrm{e}} K_{\mathrm{ce}}}{A_{\mathrm{p}}^{2}}+\frac{B_{\mathrm{p}} V_{0}}{E_{0} A_{\mathrm{p}}^{2}}\right) s^{2}+\left(1+\frac{K V_{0}}{E_{0} A_{\mathrm{p}}^{2}}+\frac{B_{\mathrm{p}} K_{\mathrm{ce}}}{A_{\mathrm{p}}^{2}}\right) s+\frac{K_{\mathrm{ce}} K}{A_{\mathrm{p}}^{2}}
\end{aligned}
$$

The dynamic structural diagram of the hydraulic AGC system is shown in Figure 2. The main parameters used in the simulation model are shown in Table 1.

\section{Controller Design}

Based on the dynamic model of the hydraulic AGC system, a sliding mode controller is designed to realize position control.

The State-space equations of the AGC system can be described as 


$$
\dot{x}=A \dot{x}+B u
$$

where $u$ is the control input.

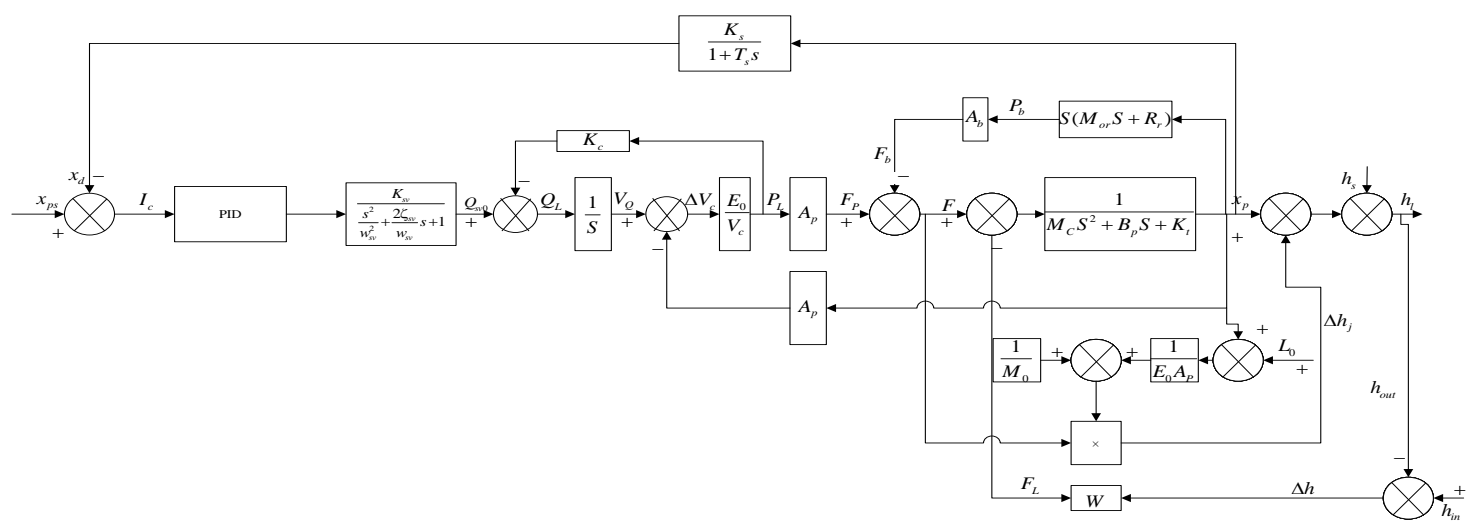

Figure 2. Dynamic Structural Diagram of Hydraulic AGC System

Table 1. Main Parameters in Model

\begin{tabular}{cccc}
\hline variable & physical significance & unit & value \\
\hline$M_{\mathrm{e}}$ & total mass of the moving parts in rolls & $\mathrm{kg}$ & $7.4 \times 10^{4}$ \\
$B_{\mathrm{p}}$ & the viscosity coefficient of moving parts such as piston and load & $(\mathrm{Ns}) / \mathrm{m}$ & $3.6 \times 10^{7}$ \\
$K$ & stiffness coefficient of elastic load & $\mathrm{N} / \mathrm{m}$ & $6.4 \times 10^{7}$ \\
$V_{0}$ & initial volume of the controlled chamber & $\mathrm{m}^{3}$ & 0.041785 \\
$W$ & plastic stiffness coefficient of the rolled piece & $\mathrm{N} / \mathrm{m}$ & $9.43 \times 10^{8}$ \\
$A_{\mathrm{p}}$ & area of the hydraulic cylinder piston & $\mathrm{m}^{2}$ & 0.95 \\
$A_{\mathrm{b}}$ & working area of the rod cavity & $\mathrm{m}^{2}$ & 0.708 \\
$P_{\mathrm{b}}$ & back-pressure of the rod cavity & $\mathrm{MPa}$ & 2 \\
$V_{0}$ & initial volume of the controlled chamber & $\mathrm{m}^{3}$ & 0.041785 \\
$K_{\mathrm{c}}$ & pressure flow factor & $\mathrm{m}^{3} / \mathrm{Ns}$ & $8 \times 10^{-12}$ \\
$E_{0}$ & elasticity modulus of the fluid & $\mathrm{MPa}$ & 800 \\
$K_{\mathrm{ce}}$ & internal leakage coefficient of the hydraulic cylinder & $\mathrm{m}^{5} / \mathrm{Ns}$ & $1.16 \times 10^{-10}$ \\
\hline
\end{tabular}

Suppose the setting position signal is denote as $r$. if we choose the real position signal $x_{\mathrm{p}}$ and its first derivative, second derivative as state variables, that is $x_{1}=x_{\mathrm{p}}$, then the state equation of the position system can be derived as

$$
\begin{aligned}
& \dot{x}_{1}=x_{2} \\
& \dot{x}_{2}=x_{3} \\
& \dot{x}_{3}=-3 \times 10^{-11} x_{1}-0.233 x_{2}-486 x_{3}+0.5 u
\end{aligned}
$$

The position tracking error and its derivative, second derivative are 
$e=r-x_{1}$

$\dot{e}=\dot{r}-x_{2}$

$\ddot{e}=\ddot{r}-x_{3}$

Let $E=\left[\begin{array}{lll}e & \dot{e} & \ddot{e}\end{array}\right]^{\mathrm{T}}$, then the switching function of the sliding model control can described as

$s=C \times E=c_{1} e+c_{2} \dot{e}+c_{3} \ddot{e}$

where $C=\left[\begin{array}{lll}c_{1} & c_{2} & c_{3}\end{array}\right]$ is the switch coefficient matrix.

The sliding mode control law is designed as

$u=(\alpha|e|+\beta|\dot{e}|) \operatorname{sign}(s)$

For comparing the control effects of different control schemes, PID controller for the position control system is also designed. To realize good control effect, tuning PID controller parameters correctly for the system is essential. In most cases, however, tuning PID control parameters is very a difficult task. Therefore, it's difficult to achieve the optimal state under field conditions in the actual production. Ziegler-Nichols method has been developed as an alternative method for PID parameter tuning. This method can be very accurate for the controller to determine the parameters. In this paper, the PID controller for the hydraulic cylinder is designed based on Ziegler-Nichols method [20-21], and its transfer function is

$G_{\mathrm{c}}(s)=500\left(1+\frac{1}{10 s}\right)$

\section{Results and Discussion}

To verify the control effect of the designed controller, simulation operation was carried out in the MATLAB/Simulink platform. The setting position is chosen as $r=1 \mathrm{~m}$.

The simulation results corresponding to PID control are shown in Figure 3. Although the PID controller parameters have been tuned by reasonable tuning way, the control effect is still far from satisfactory. To a certain extent, PID control can track the given position signal, but the response time to reach steady state is too long. The responding time of PID controller is about 40s. 
International Journal of Control and Automation

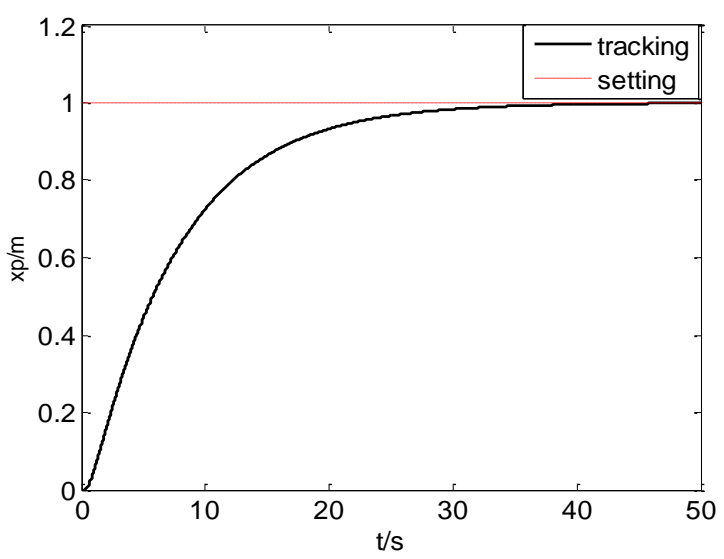

Figure 3. Displacement Response without Disturbance Under PID Control
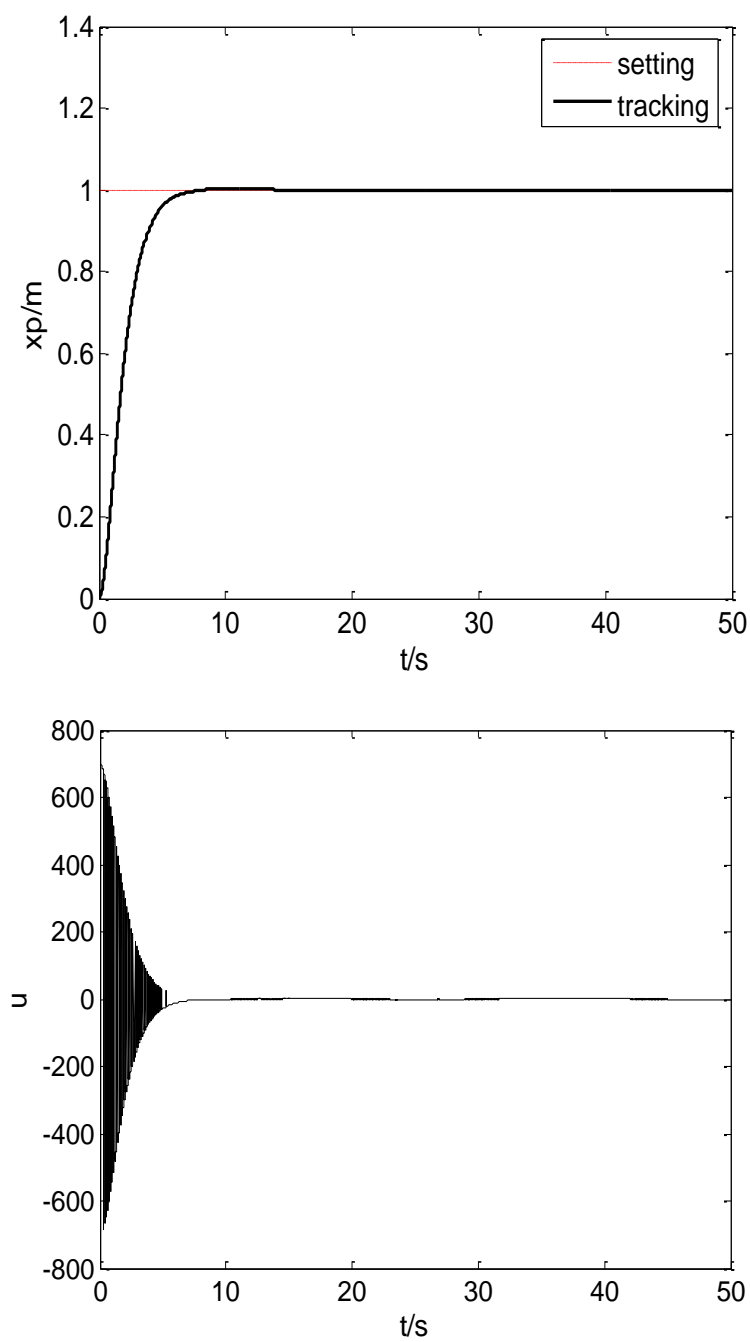

Figure 4. Displacement Response and Control Law of SMC without Disturbance (Switching Factor $\left.C=\left[\begin{array}{lll}1 & 2 & 1\end{array}\right]\right)$ 
Simulation results corresponding to sliding mode control are shown in Figure 4 to Figure 5. In the simulation, $\alpha=700, \beta=0.6$.

It can be seen from Figure 4 and Figure 5 that the whole control effect of SMC is superior to that of PID control. When the sliding mode control is used, the responding time is about $8 \mathrm{~s}$, which is significantly less than that of PID control. Sliding mode variable structure control has outstanding advantages on tracking speed and steady precision, and these make it suitable for controlling the rolling mill hydraulic AGC system.
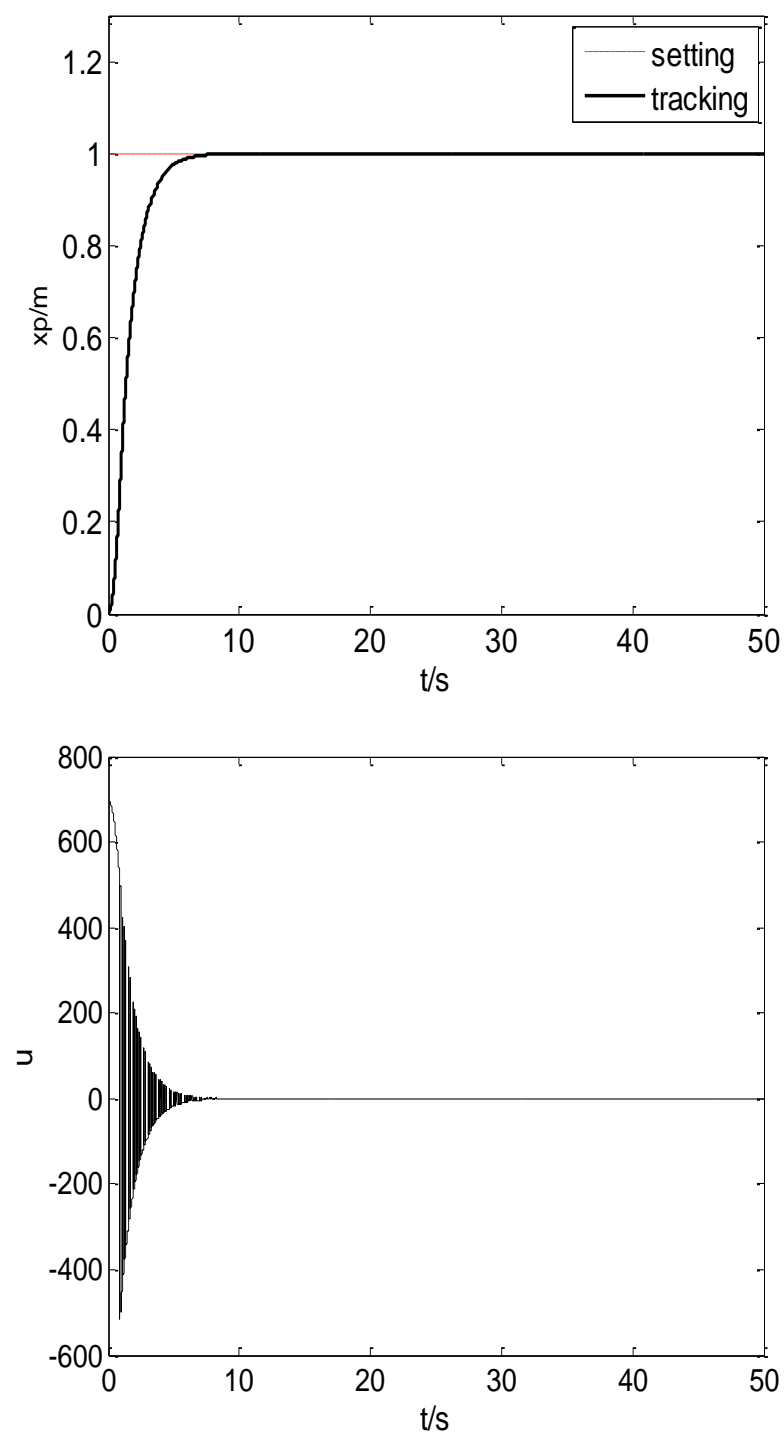

Figure 5. Displacement Response and Control Law of SMC without Disturbance (Switching Factor $C=\left[\begin{array}{lll}2 & 2.5 & 0.08\end{array}\right]$ )

In order to investigate the controllers' capacity of resisting disturbance, a step disturbance signal is put on the load pressure at the time of $40 \mathrm{~s}$, and the value of the disturbance is o.5 MPa. The corresponding simulation running results are shown in Figure 6 to Figure 7. 


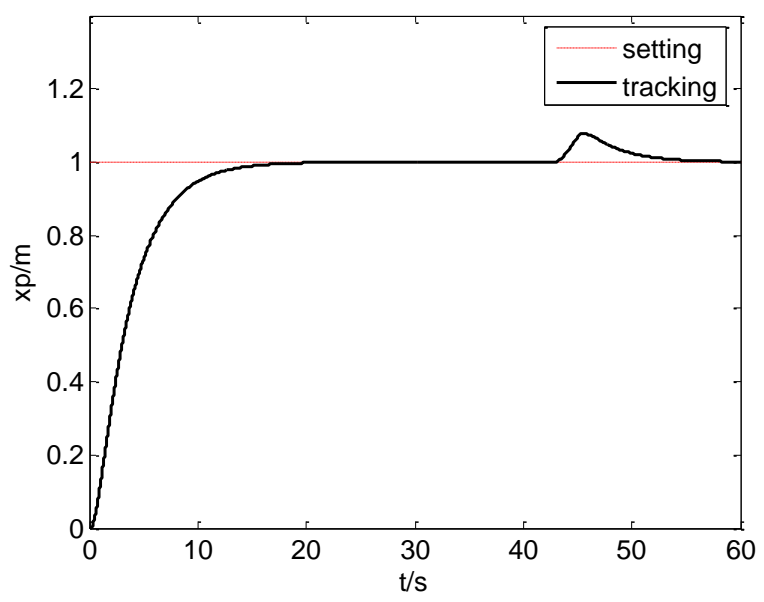

Figure 6. Displacement Response with Disturbance under PID Control

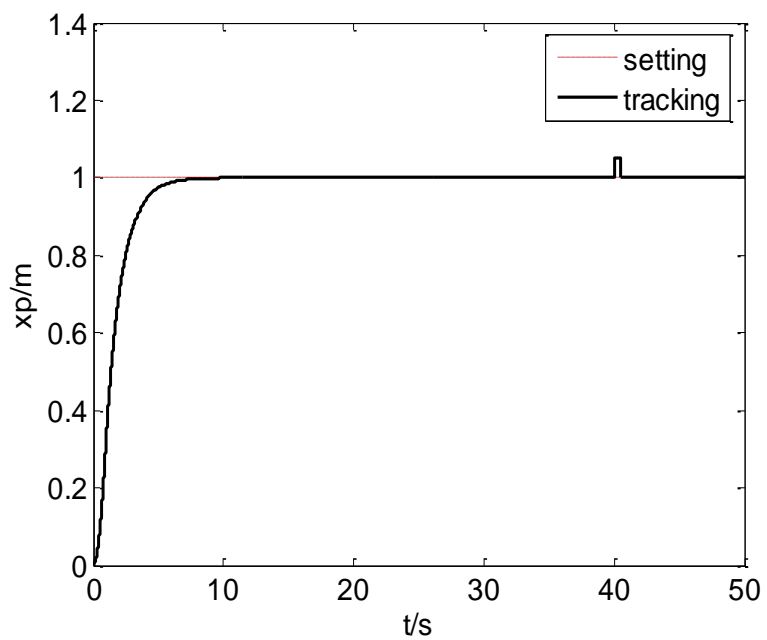

Figure 7. Displacement Response with Disturbance under SMC Control

Some phenomena can be observed from Figure 6 to Figure 7. If a general PID controller is used in the AGC system, disturbance will make the system deviate from the setting steady state distinctly. While if we use sliding mode controller to the AGC system, SMC can make the system quickly return to the setting steady state after experiencing a brief deviation from the setting state. Sliding mode control has good disturbance rejection capability.

\section{Conclusions}

For a typical nonlinear system such as the hydraulic pressure automatic gauge control system of a strip rolling mill, time delay, time-varying, large inertia and multivariable are its inherent characteristics. Using sliding mode control to realize hydraulic position control can get good control effect. 


\section{Acknowledgements}

This work was supported by the National Key Technology Research and Development Program of China under Grant 2012BAF09B01, and the Science and Technology Research Project of Liaoning Education Department under Grant L2012140.

\section{References}

[1] A. E. Sushko, "Methodology of Introducing Hardware/Software Systems for Monitoring And Diagnosing Rolling Mills", Metallurgist, vol. 54, no. 5-6, (2010), pp. 367-374.

[2] G. Y. Li and M. Dong, "A Wavelet and Neural Networks Based on Fault Diagnosis for HAGC System of Strip Rolling Mill”, Journal of Iron and Steel Research International, vol. 18, no. 1, (2011), pp. 31-35.

[3] B. H. Yang, W. D. Yang, L. G. Chen and L. Qu, "Dynamic Optimization of Feedforward Automatic Gauge Control Based on Extended Kalman Filter", Journal of Iron and Steel Research International, vol. 15, no. 2 , (2008), pp. 39- 42.

[4] Y. Fang, Z. X. Jiao, W. B. Wang and P. Z. Shao, "Adaptive Backstepping Sliding Mode Control for Rolling Mill Hydraulic Servo Position System”, Electric Machines and Control (in China), vol. 15 no. 10, (2011), pp. 95-100.

[5] Z. Wu, Q. Xia, Y. Peng and J. Sun, "Backstepping Dynamic Surface Control for High-order Nonlinear Hydraulic Roll Gap System”, Chinese Journal of Scientific Instrument (in China), vol. 33, no. 4, (2012), pp. 949-954.

[6] J. X. Li, Y. M. Fang and S. L. Shi, "Robust Output-Feedback Control for Hydraulic Servo-Position System of Cold-Strip Rolling Mill", Control Theory \& Applications (in China), vol. 29, no. 3, (2012), pp. 331-336.

[7] Z. Li, "Model Reference Adaptive Controller Design Based on Fuzzy Inference System", Journal of Information \& Computational Science, vol. 8, no. 9, (2011), pp. 1683-1693.

[8] T. Gong and L. Qi, "Novel ARM-based Gauge Control System with Fuzzy PI Controller", International Journal of Multimedia and Ubiquitous Engineering, vol. 7, no. 2, (2012), pp. 527-532.

[9] F. G. Areed, M. A. Badr, S. F. Saraya, M. S. Elksasy and M. M. Abdelsalam, "Decoupled Sliding Mode Control for a Multivariable Nonlinear System", International Journal of Computer Applications, vol. 55, no. 6, (2012), pp. 25-32.

[10] T. C. Kuo, Y. J. Huang and B. W. Hong, "Design of Adaptive Sliding Mode Controller for Robotic Manipulators Tracking Control”, World Academy of Science, Engineering and Technology, vol. 5, (2011), pp. 190-194.

[11] E. M. Navarro-López, D. Cortés and C. Castro, "Design of practical sliding-mode controllers with constant switching frequency for power converters”, Electric Power Systems Research, vol. 79, no. 5, (2009), pp. 796802.

[12] M. R. Soltanpour and M. M. Fateh, "Sliding Mode Robust Control of Robot Manipulator in the Task Space by Support of Feedback Linearization and BackStepping Control”, World Applied Sciences Journal, vol. 6, no. 1, (2009), pp. 70-76.

[13] S. C. Tan, Y. M. Lai and C. K. Tse, "General Design Issues of Sliding-Mode Controllers in DC-DC Converters", IEEE Transactions on Industrial Electronics, vol. 55, no.3, (2008), pp. 1160-1175.

[14] Y. W. He, W. S. Xu and Y. A. Cheng, "Novel Scheme for Sliding-Mode Control of DC-DC Converters with a Constant Frequency Based on the Averaging Model", Journal of Power Electronics, vol. 10, no. 1, (2010), pp. $1-8$.

[15] A. Kolabi and S. Sofalgar, "Application of Sliding Mode Control in Single Machine Infinite Bus System (SMIB)", Australian Journal of Basic and Applied Sciences, vol. 6, no. 5, (2012), pp. 165-174.

[16] D. Biel, E. Fossas, F. Guinjoan, E. Alarcón and A. Poveda, "Application of Sliding-Mode Control to the Design of a Buck-Based Sinusoidal Generator", IEEE Transactions on Industrial Electronics, vol. 48, no. 3, (2001), pp. 563-571.

[17] A. Rhif, "Stabilizing Sliding Mode Control Design and Application for a DC Motor: Speed Control", International Journal of Instrumentation and Control Systems, vol. 2, no. 1, (2012), pp. 39-48.

[18] F. G. Rossomando and J. D. Filho, "Modelling and Control of a Hot Rolling Mill", Latin American Applied Research, vol. 36, (2006), pp. 199-204.

[19] S. Khosravi, A. Afshar and F. Barazandeh, "Design of a Fuzzy Feed-forward Controller for Monitor HAGC System of Cold Rolling Mill”, World Academy of Science, Engineering and Technology, vol. 5, (2011), pp. 2086-2091.

[20] A. Yang and Q. Ouyang, "Modeling and Simulation of Hydraulic AGC System of Rolling Gap Control", Machine Tool \& Hydraulics (in China), vol. 36, no. 9, (2008), pp. 243-247. 
International Journal of Control and Automation

Vol.7, No.8 (2014)

[21] Z. Li, "Model Reference Adaptive Controller Design Based on Fuzzy Inference System", Journal of Information \& Computational Science, vol. 8, no. 9, (2011), pp. 1683-1693.

[22] B. Q. Jin and D. B. Chen, "Improvement of Hydraulic Edge Position Control System by Proportion Sliding Mode of Self-tuning Switching Gain”, Research Journal of Applied Sciences, Engineering and Technology, vol. 4, no. 41, (2012), pp. 4237-4244. 